(2) Open Access Full Text Article

REVIEW

\title{
Impact of chronotype on athletic performance: current perspectives
}

\author{
This article was published in the following Dove Press journal: \\ ChronoPhysiology and Therapy \\ 31 March 2017 \\ Number of times this article has been viewed
}

\author{
Laura C Roden' \\ Trinity D Rudner ${ }^{\prime}$ \\ Dale E Rae ${ }^{2}$ \\ 'Department of Molecular and Cell \\ Biology, ${ }^{2}$ Division of Exercise Science \\ and Sports Medicine, University of \\ Cape Town, Cape Town, South Africa
}

\begin{abstract}
Many of the physiological and psychological qualities that influence an athlete's performance show diurnal variation. Humans present with a temporal phenotype, their chronotype that affects their preference for morning or evening activity. There is considerable interindividual variation in the phase relationship of physiological processes, hormones and core body temperature to external time due to chronotype. This can lead to differences in the times of peaks of physical performance within a day. Chronotype is thus an important variable in determining optimal times for training and competition and may affect an athlete's choice of sport or his/ her success in it. We review the evidence that chronotype influences athletic performance and speculate about how athletes might overcome the effects of chronotype when their schedule is out of phase with their circadian rhythm.
\end{abstract}

Keywords: chronotype, circadian, athletes, training, training time-of-day, individual sports

\section{Introduction}

In the era of professional sport, athletes, coaches and support staff pay close attention to the science, medicine and psychology behind athletic performance, as even the smallest gains in performance are considered to be significant. ${ }^{1}$ Understanding the individuality of an athlete may help tailor his or her training to maximize performance. One factor that renders each individual unique is his/her innate circadian rhythm. ${ }^{2}$ Humans are diurnal, and society and work schedules are broadly based on the circadian behavioral rhythm of diurnal activity and nocturnal rest. However, if people are free to choose when diurnal activity starts, considerable variation in preferred wake, sleep and activity timing is observed. This temporal phenotype, known as chronotype, ${ }^{3}$ reflects subtle variations in a person's innate circadian rhythm. Circadian rhythms are generated by molecular interactions, including transcription-translation feedback loops, and as such, variations in period, phase and amplitude are largely genetically determined. ${ }^{4-6}$ There are circadian rhythms in cellular, biochemical and physiological processes within the body, and as a consequence diurnal variations in both cognitive ${ }^{7}$ and physical performance exist. ${ }^{8,9}$ Recent research has highlighted the fact that the chronotype distribution observed in athletes may be different to that of nonathletes, ${ }^{10-14}$ yet there is little research investigating the association between chronotype and athletic performance. The following three pertinent questions have recently been posed: 1) does chronotype affect performance? 2) Does athletic activity affect chronotype? 3 ) Is this a bidirectional relationship? ${ }^{15}$ The aim of this review is to consider the evidence around these questions.
Correspondence: Laura C Roden Department of Molecular and Cell Biology, University of Cape Town, Private Bag X3 Rondebosch, 770I, Cape Town, South Africa

Tel +27 2l 6505322

Email laura.roden@uct.ac.za 


\section{Chronotype}

Chronotype is understood to reflect a spectrum of behaviors ranging from an extreme preference for morning activity to an extreme preference for evening activity. ${ }^{16}$ Individuals with a morning-type chronotype typically wake earlier in the morning, are more alert in the earlier part of the day and choose earlier bedtimes. Evening-types on the other hand prefer later rising times, are more alert in the evening or night and have later bedtimes. ${ }^{17}$ Neither-types occupy the middle of the spectrum, and one might speculate that they are more flexible since they do not show strong preferences for either mornings or evenings. Chronotype is readily assessed using tools such as the Horne-Östberg Morningness-Eveningness Personality Questionnaire (MEQ) ${ }^{18}$ the Munich Chronotype Questionnaire (MCTQ) ${ }^{19}$ and the Composite Scale of Morningness (CSM) ${ }^{20}$ While extreme chronotypes often attract the most attention, neither-types are the most common. Most adult populations worldwide show either a normal distribution of chronotype or a predominance of neither-types, with the percentage of neither-types ranging from $46 \%$ to $67 \%$, that of morning-types from $7 \%$ to $40 \%$ and that of eveningtypes from $6 \%$ to $27 \%{ }^{2,12,21-30}$

\section{Chronotype in athletes}

Some studies exploring chronotype in athletic individuals indicate that there is an overrepresentation of morning-types. For example, $71 \%$ of Brazilian Paralympic athletes $(\mathrm{n}=27)$ were classified as morning-types. ${ }^{10}$ Similarly, 72\%, 67\% and $59 \%$ of well-trained South African (SA) male cyclists $(\mathrm{n}=125)$, runners $(\mathrm{n}=119)$ and Ironman triathletes $(\mathrm{n}=49)$, respectively, were also classified as morning-types. ${ }^{11}$ These results, which have been consistently duplicated in further studies of well-trained, individual athletes, ${ }^{12,13,31}$ suggest that athletic groups contain a higher proportion of morning-types than that typically reported in the general population. A recent investigation of 114 elite individual and team sport athletes, however, observed a more normal distribution of chronotype, with neither-types predominating in all groups but the triathletes. ${ }^{14}$ Closer inspection of the data suggests that chronotype distribution in athletes may be dependent on the type of sport, with clear differences existing between team and individual sports, a finding that has been shown previously. ${ }^{32}$ Investigating the reasons behind this apparent sport-specific chronotype distribution is beyond the scope of this review. Rather, the focus here is the extent to which chronotype may influence performance and vice versa. Do morning-types perform better than evening-types in some sports $^{12}$ and consequently go on to become elite athletes in those sports, thus skewing the chronotype distributions in those populations? Or does being habitually physically active at a particular time of day shift chronotype, since physical activity can phase advance core body temperature (CBT) and melatonin rhythms ${ }^{33,34}$

\section{Chronotype and diurnal variation}

Interestingly, chronotype and the subjective measure of diurnal preference via questionnaires correlate with our endogenous circadian period of CBT and melatonin measured in constant routine, ${ }^{35}$ and the timing of the temperature, melatonin and cortisol peaks in individuals with a preference for morning activity is earlier than that in individuals with a preference for evening activity. ${ }^{23,36-38}$ Many studies have concluded that physical performance, or markers thereof, peaks in the afternoon/evening. ${ }^{9,39}$

A number of studies have measured the response to exercise at different times of day and found that diurnal variation is specific to chronotype. For example, evening-types reached higher $\mathrm{VO}_{2}$ max values, ${ }^{40}$ had higher cortical and spinal excitability levels and generated more torque ${ }^{41}$ in the evening compared with morning and had slower heart rate recoveries in the morning than in the evening..$^{42}$ In contrast, the morning-types in these same studies showed no diurnal variation in $\mathrm{VO}_{2} \max ,{ }^{40}$ heart rate recovery ${ }^{42}$ and torque, ${ }^{41}$ but cortical excitability was higher in the morning and spinal excitability higher in the evening. ${ }^{41}$ Morning-types may also perceive exercise to be harder in the evening compared with morning. ${ }^{43}$ In contrast to Hill et al,,$^{40}$ a recent study in competitive athletes indicated that morning-types had earlier time-of-day peaks in $\mathrm{VO}_{2}$ max estimated from a bleep test and less diurnal variation, while the evening-types had later time-of-day peaks and more diurnal variation. ${ }^{44}$ In contrast to all these studies, one study has found no effect of chronotype on diurnal variation in performance, as measured by response to maximal exercise..$^{45}$

Only two studies have assessed diurnal variation in directly measured performance (e.g., time trial), taking chronotype into account. In a study of 16 university rowers, morning-types had faster $2000 \mathrm{~m}$ ergometer time trial times in the morning compared to those in the evening, while the neither-types and evening-types displayed no diurnal variation in performance. ${ }^{46}$ Similarly, among 26 trained adult swimmers, the morning-types had faster $200 \mathrm{~m}$ time trials in the morning, while neither-types swam faster in the evening time trial. ${ }^{13}$ Based on these collective data, it seems reasonable to speculate that the circadian biology of evening-types may favor competition in the latter part of the day, while 
morning-types may be better suited to events taking place earlier in the day. What none of these data show, however, is whether one specific chronotype outperforms another at any given time of day.

\section{Does chronotype influence athletic performance?}

To the best of our knowledge, only one study has directly compared performance of different chronotypes during an event. Marathon race time and chronotype were measured in trained, recreational SA $(n=96)$ and Dutch $(n=90)$ marathon runners. In both groups, morning-types were overrepresented (SA: 65\% and Dutch: 50\%), and evening-types were the minority (SA: 3\% and Dutch: 6\%). While the SA runners with higher chronotype scores also had faster marathon race times, the same was not true for the Dutch runners. ${ }^{12}$ One explanation for this observation may be that as the SA marathon started earlier than the Dutch event (SA: 06:00 and Dutch: 11:00), the SA event may have favored morning-types to a greater extent than the Dutch event. Another factor that may moderate performance differences between chronotype groups at any given time of day might be habitual training time-of-day. Does training time-of-day modify diurnal variation in performance differently for morning-, neither- and evening-types?

\section{Chronotype and athletic performance: the moderating effect of training time-of-day}

There is some evidence that diurnal variation in laboratorymeasured performance is modified by habitual training time-of-day. For example, morning training removes diurnal variation in short-term maximal performance, while evening training enhances this variation. ${ }^{9}$ There is also evidence to suggest that when free to choose, morning-types prefer training in the morning, evening-types in the evening and neither-types are less polarized. ${ }^{11,12}$ In addition, given the observation that individuals report lower ratings of perceived exertion in exercise sessions performed at their preferred time of day, ${ }^{13,43}$ one might speculate that the ability to increase training intensity at a preferred time of day might in turn improve training adaptation for that time of day.

In a group of morning- and neither-type swimmers, Rae et al $^{13}$ measured $200 \mathrm{~m}$ time trial performance in swimmers and observed that those who habitually trained in the morning had faster morning time-trial times, while those who usually trained in the evening were faster in the evening time trial. Furthermore, morning-type swimmers who trained in the morning had faster morning trials, neither-type swimmers who trained in the morning and morning-type swimmers who trained in the evening had little diurnal variation in performance, while neither-type swimmers who trained in the evening were faster in the evening time trial. While the effect of training time-of-day on performance in different chronotype groups was not explicitly investigated, Brown et $\mathrm{al}^{46}$ also provided some indirect evidence for this effect. In competitive university rowers who were required to train in both the morning and evening on most days of the week, morning-types were $4.8 \mathrm{~s}(1.1 \%)$ faster in the morning time trial, while the neither- and evening-types had no diurnal variation in performance. Together, these studies suggest that habitual training time-of-day modifies diurnal variation in performance to different extents depending on chronotype. Not only does morning training appear to reduce diurnal variation in performance of neither- and evening-types, but morning-types may also benefit more when competition is scheduled for the morning.

Training time-of-day and chronotype may also have an influence on sleep. In a recent study of university soccer players, the quality of sleep in morning- and evening-types was measured following morning (08:00) and evening (20:00) high-intensity interval training sessions. Poorer sleep quality (reduced total sleep time, more time awake during the sleep period and poorer sleep efficiency) was recorded in morning-types following the 20:00 training session, while sleep quality after the 08:00 session was similar for both groups. ${ }^{47}$ Since sleep following training is understood to be an important factor for recovery, ${ }^{48}$ reduced sleep quality following evening training sessions may negatively impact subsequent performance in morning-types.

\section{Does athletic activity influence chronotype?}

The premise here would be that through regular participation in training sessions and sporting events, one's preference for, or aversion to, activity at a particular time of day changes, thus shifting one's chronotype. An anecdotal report by Brown et $\mathrm{al}^{46}$ indicated that nearly half of the rowers who initially joined the squad dropped out after just three sessions, owing to the early morning training schedule. The first factor to consider is the extent to which chronotype is modifiable. Most studies that have assessed the heritability of chronotype in populations have estimated it to be $\sim 50 \% .{ }^{49-51}$ However, two studies have arrived at much lower estimates of $14 \%$ and $23 \%,{ }^{52,53}$ and notably chronotype was not normally distributed in these two populations. In the study of an Amazonian 
community, ${ }^{52}$ the authors note that their estimate is inaccurate as the parent/offspring regression coefficients were negative. Within the Amazonian population, Aguiar et al ${ }^{52}$ noted a high degree of morningness (95\%), suggesting a strong masking effect of the socioeconomic, and perhaps climatic, environment on the expression of overt chronotype. Klei et al's study ${ }^{53}$ was of an agrarian community of Hutterites in Manitoba. It is likely in this population too that the environment had a masking effect on chronotype, as there was a high tendency toward morningness, which was attributed to their farming lifestyle and communal breakfasting at a fixed time.

As chronotype is a complex phenotype based on circadian behavior defined by multiple molecular interactions, it is likely to be a polygenic trait ${ }^{54}$ with each variant contributing more or less to the ultimate phase preference. Many studies have, inconsistently, identified single circadian clock gene associations with chronotype,${ }^{55-58}$ while some recent genomewide association studies have indicated associations of variants at multiple loci with morningness. ${ }^{59,60}$ The polygenic nature of the trait combined with the potential for masking due to environmental and socioeconomic effects may explain the conflicts in the single-gene association studies. Studies including the confirmed and novel loci combinations from the genome-wide association studies ${ }^{59,60}$ may overcome these inconsistencies and provide more information about the role of the environment in determining diurnal preference.

The long-term consistency of chronotype was evaluated in 567 former elite Finnish athletes, for whom diurnal type

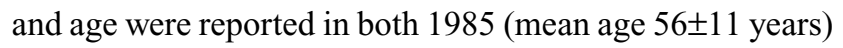
and 2008 (mean age $73 \pm 6$ years). ${ }^{61}$ As expected, there was an age-associated reduction in the number of evening chronotypes over the 20 -year period. There was also a shift from a predominance of morning-types to a predominance of moderate morning-types. Potentially, this indicates that the former athletes initially displayed chronotypes reflecting their habitual training or competitive behaviors, while as time passed this effect was lost, as they reduced their training levels or even daily physical activity.

A shift in chronotype due to "conditioning" of athletes to their habitual training times may occur for those who are neither-types. In a small, short-term study, Chtourou et al ${ }^{62}$ found that training time-of-day could modify chronotype. In this study, moderate morning-type soccer players who undertook habitual evening training during Ramadan experienced a shift in their MEQ scores over time, such that by the end of the study they were reclassified as moderate evening-types. In the same experiment, the moderate morning-type players who were assigned morning training showed no change in their chronotype. While it is quite possible that athletic performance may act as a behavioral modifier of chronotype, no studies have investigated this concept. Therefore, there is a need for future studies directly comparing the performance of morning-, neither- and evening-type athletes in real-life competition, as well as longitudinal studies tracking changes in performance and chronotype over time.

\section{Recommendations for athletes and coaches}

The scheduling of events is for the most part beyond the control of athletes, coaches and team managers. In many instances, competition time is defined by television broadcasting schedules and in others by the medical need to avoid exercise at the warmest part of the day. Further complicating matters is the fact that in some sports, such as swimming and athletics, qualifying heats may take place in the earlier part of the day, while finals are often scheduled in the evening. Understanding the potential impact of performance at a given time of day on athletes with different chronotypes is important. Based on the available evidence, it appears that evening-types and neither-types are able to achieve their best performances in the latter part of the day and that this advantage can be maximized by training in the afternoons or evenings. Morning-types, however, are likely to achieve best performances in the earlier part of the day, especially when habitual training time coincides with morning competition time.

There are two important things to consider when thinking about how to incorporate this information into practice. First, having an athlete perform at his/her best during a training session may maximize adaptation to training, which in turn is critical to improve overall performance. So, if event time-ofday is not critical, it might be more beneficial for an athlete to train at the time that they feel best, and that is likely to be in phase with their innate circadian rhythm. The second point relates to competition time-of-day. For morning-based events, as are typically observed in individual endurance events, morning-types would almost certainly benefit from morning-training sessions. Neither- and evening-types may benefit from a combination of sessions: evening-sessions to maximize training adaptation but some morning sessions to acclimate their bodies to performance at what for them is a "less favored" time-of-day. Outdoor, morning training sessions in bright sunlight may be beneficial in shifting the circadian phase ${ }^{63}$ of evening-types, allowing earlier sleep times. ${ }^{64}$ The reverse may hold true for evening-based events. However, the effect of evening training sessions on sleep 
quality in morning-types ${ }^{47}$ must be borne in mind when devising training plans, and implementation of a training schedule that includes evening sessions should be done sufficiently far in advance of a night-time event or series of events to allow adaptation $^{62}$ to occur.

\section{Disclosure}

The authors report no conflicts of interest in this work.

\section{References}

1. Currell K, Jeukendrup AE. Validity, reliability and sensitivity of measures of sporting performance. Sports Med. 2008;38(4):97-316.

2. Roenneberg T, Kuehnle T, Juda M, et al. Epidemiology of the human circadian clock. Sleep Med Rev. 2007;11(6):429-438.

3. Ehret CF. The sense of time: evidence for its molecular basis in the eukaryotic gene-action system. Adv Biol Med Phys. 1974;15:47-77.

4. Hamet P, Tremblay J. Genetics of the sleep-wake cycle and its disorders. Metabolism. 2006;55(10 suppl 2):S7-S12.

5. von Schantz M. Phenotypic effects of genetic variability in human clock genes on circadian and sleep parameters. J Genet. 2008;87(5):513-519.

6. Partch CL, Green CB, Takahashi JS. Molecular architecture of the mammalian circadian clock. Trends Cell Biol. 2014;24(2):90-99.

7. Kline CE, Durstine JL, Davis JM, Moore TA, Devlin TM, Youngstedt SD. Circadian rhythms of psychomotor vigilance, mood, and sleepiness in the ultra-short sleep/wake protocol. Chronobiol Int. 2010;27(1):161-180.

8. Drust B, Waterhouse J, Atkinson G, Edwards B, Reilly T. Circadian rhythms in sports performance - an update. Chronobiol Int. 2005;22(1):21-44.

9. Chtourou H, Souissi N. The effect of training at a specific time of day: a review. J Strength Cond Res. 2012;26(7):1984-2005.

10. Silva A, Queiroz SS, Winckler C, et al. Sleep quality evaluation, chronotype, sleepiness and anxiety of Paralympic Brazilian athletes. $\mathrm{Br} J$ Sports Med. 2012;46(2):150-154.

11. Kunorozva L, Stephenson KJ, Rae DE, Roden LC. Chronotype and PERIOD3 variable number tandem repeat polymorphism in individual sports athletes. Chronobiol Int. 2012;29(8):1004-1010.

12. Henst RH, Jaspers RT, Roden LC, Rae DE. A chronotype comparison of South African and Dutch marathon runners: the role of scheduled race start times and effects on performance. Chronobiol Int. 2015;32(6):858-868.

13. Rae DE, Stephenson KJ, Roden LC. Factors to consider when assessing diurnal variation in sports performance: the influence of chronotype and habitual training time-of-day. Eur J Appl Physiol. 2015;115(6):1339-1349.

14. Lastella M, Roach GD, Halson SL, Sargent C. The chronotype of elite athletes. J Hum Kinet. 2016;54:219-225.

15. Kuffer L, Groß JV, Erren M, Erren TC. Chronotype, sports and public health. Chronobiol Int. 2015;32(9):1325-1327.

16. Natale V, Cicogna PC. Morningness-eveningness dimension: is it really a continuum? Pers Individ Differ. 2002;32:809-816.

17. Adan A, Archer SN, Hidalgo MP, Di Milia L, Natale V, Randler C. Circadian typology: a comprehensive review. Chronobiol Int. 2012;29(9):1153-1175.

18. Horne JA, Ostberg O. A self-assessment questionnaire to determine morningness-eveningness in human circadian rhythms. Int J Chronobiol. 1976;4(2):97-110.

19. Roenneberg T, Wirz-Justice A, Merrow M. Life between clocks - daily temporal patterns of human chronotypes. J Biol Rhythms. 2003;18(1):80-90.

20. Smith CS, Reilly C, Midkiff K. Evaluation of three circadian rhythm questionnaires with suggestions for an improved measure of morningness. J Appl Psychol. 1989;74(5):728-738.
21. Adan A, Almirall $\mathrm{H}$. The influence of age, work schedule and personality on morningness dimension. Int J Psychophysiol. 1992;12(2):95-99.

22. Adan A, Natale V. Gender differences in morningness-eveningness preference. Chronobiol Int. 2002;19(4):709-720.

23. Baehr EK, Revelle W, Eastman CI. Individual differences in the phase and amplitude of the human circadian temperature rhythm: with an emphasis on morningness-eveningness. J Sleep Res. 2000;9(2):117-127.

24. Kabrita CS, Hajjar-Muça TA, Duffy JF. Predictors of poor sleep quality among Lebanese university students: association between evening typology, lifestyle behaviors, and sleep habits. Nat Sci Sleep. 2014;13(6):11-18.

25. Zavada A, Gordijn MC, Beersma DG, Daan S, Roenneberg T. Comparison of the Munich chronotype questionnaire with the Horne-Ostberg's Morningness-Eveningness Score. Chronobiol Int. 2005;22(2):267-278.

26. Shawa N, Roden LC. Chronotype of South African adults is affected by solar entrainment. Chronobiol Int. 2016;33(3):315-323.

27. Vitale JA, Roveda E, Montaruli A, et al. Chronotype influences activity circadian rhythm and sleep: differences in sleep quality between weekdays and weekend. Chronobiol Int. 2015;32(3):405-415.

28. Yu JH, Yun $\mathrm{CH}$, Ahn JH, et al. Evening chronotype is associated with metabolic disorders and body composition in middle-aged adults. J Clin Endocrinol Metab. 2015;100(4):1494-1502.

29. Barclay NL, Eley TC, Parsons MJ, Willis TA, Gregory AM. Monozygotic twin differences in non-shared environmental factors associated with chronotype. J Biol Rhythms. 2013;28(1):51-61.

30. Osland TM, Bjorvatn BR, Steen VM, Pallesen SI. Association study of a variable-number tandem repeat polymorphism in the clock gene PERIOD3 and chronotype in Norwegian university students. Chronobiol Int. 2011;28(9):764-770.

31. Lastella M, Roach GD, Hurem D, Sargent C. Does chronotype affect elite athletes' capacity to cope with the training demands of elite triathlon. In: 7th Annual Meeting of the Australasian Chronobiology Society, At Adelaide, Australia, Volume: Living in a 24/7 World: The Impact of Circadian Disruption on Sleep, Work and Health; 2010; Vol. 24; Issue no. 7:25-28.

32. Zani A, Rossi B, Borriello A, Mecacci L. Diurnal interindividual differences in the habitual activity pattern of top level athletes. $J$ Sports Med Phys Fitness. 1984;24(4):307-310.

33. Eastman CI, Hoese EK, Youngstedt SD, Liu L. Phase-shifting human circadian rhythms with exercise during the night shift. Physiol Behav. 1995;58(6):1287-1291.

34. Miyazaki T, Hashimoto S, Masubuchi S, Honma S, Honma KI. Phaseadvance shifts of human circadian pacemaker are accelerated by daytime physical exercise. Am J Physiol Regul Integr Comp Physiol. 2001;281(1):R197-R205.

35. Duffy JF, Dijk DJ, Hall EF, Czeisler CA. Relationship of endogenous melatonin and temperature rhythms to self-reported preference for morning or evening activity in young and older people. J Investig Med. 1999;47(3):141-150.

36. Kerkhof GA, van Dongen HPA. Morning-type and evening-type individuals differ in the phase position of their endogenous circadian oscillator. Neurosci Lett. 1996;218(3):153-156.

37. Bailey SL, Heitkemper MM. Circadian rhythmicity of cortisol and body temperature: morningness-eveningness effects. Chronobiol Int. 2001;18(2):249-261.

38. Waterhouse J, Folkard S, Van Dongen H, et al. Temperature profiles, and the effect of sleep on them, in relation to morningness-eveningness in healthy female subjects. Chronobiol Int. 2001;18(2):227-247.

39. Thun E, Bjorvatn B, Flo E, Harris A, Pallesen S. Sleep, circadian rhythms, and athletic performance. Sleep Med Rev. 2015;23:1-9.

40. Hill DW, Cureton KJ, Collins MA, Grisham SC. Diurnal variations in responses to exercise of "morning types" and "evening types.". J Sports Med Phys Fitness. 1988;28(3):213-219.

41. Tamm AS, Lagerquist O, Ley AL, Collins DF. Chronotype influences diurnal variations in the excitability of the human motor cortex and the ability to generate torque during a maximum voluntary contraction. J Biol Rhythms. 2009;24(3):211-224. 
42. Sugawara J, Hamada Y, Nishijima T, Matsuda M. Diurnal variations of post-exercise parasympathetic nervous reactivation in different chronotypes. Jpn Heart J. 2001;42(2):163-171.

43. Kunorozva L, Roden LC, Rae DE. Perception of effort in morningtype cyclists is lower when exercising in the morning. J Sports Sci. 2014;32(10):917-925.

44. Facer-Childs E, Brandstaetter R. The impact of circadian phenotype and time since awakening on diurnal performance in athletes. Curr Biol. 2015;25(4):518-522.

45. Burgoon PW, Hollan GJ, Loy SF, Vincent WJ. A comparison of morning and evening "types" during exercise. J Appl Sport Sci Res. 1992;6(2):115-119.

46. Brown FM, Neft EE, LaJambe CM. Collegiate rowing crew performance varies by morningness-eveningness. J Strength Cond Res. 2008;22(6):1894-1900.

47. Vitale JA, Bonato M, Galasso L, et al. Sleep quality and high intensity interval training at two different times of day: a crossover study on the influence of the chronotype in male collegiate soccer players. Chronobiol Int. 2017;34(2):260-268.

48. Skein M, Duffield R, Minett GM, Snape A, Murphy A. The effect of overnight sleep deprivation after competitive rugby league matches on postmatch physiological and perceptual recovery. Int J Sports Physiol Perform. 2013;8(5):556-564.

49. Vink JM, Groot AS, Kerkhof GA, Boomsma DI. Genetic analysis of morningness and eveningness. Chronobiol Int. 2001;18(5): 809-822.

50. Barclay NL, Eley TC, Buysse DJ, Archer SN, Gregory AM. Diurnal preference and sleep quality: same genes? A study of young adult twins. Chronobiol Int. 2010;27(2):278-296.

51. von Schantz M, Taporoski TP, Horimoto AR, et al. Distribution and heritability of diurnal preference (chronotype) in a rural Brazilian family-based cohort, the Baependi study. Sci Rep. 2015;5:9214.

52. Aguiar GF, da Silva HP, Marques N. Patterns of daily allocation of sleep periods: a case study in an Amazonian riverine community. Chronobiologia. 1991;18(1):9-19.
53. Klei L, Reitz P, Miller M, et al. Heritability of morningness-eveningness and self-report sleep measures in a family-based sample of 521 Hutterites. Chronobiol Int. 2005;22(6):1041-1054.

54. Shimomura K, Low-Zeddies SS, King DP, et al. Genome-wide epistatic interaction analysis reveals complex genetic determinants of circadian behavior in mice. Genome Res. 2001;11(6):959-980.

55. Archer SN, Robilliard DL, Skene DJ, et al. A length polymorphism in the circadian clock gene period 3 is linked to delayed phase sleep syndrome and extreme diurnal preference. Sleep. 2003;26(4):413-415.

56. Barclay NL, Eley TC, Mill J, et al. Sleep quality and diurnal preference in a sample of young adults: associations with 5HTTLPR, PER3, and CLOCK 3111. Am JMed Genet B Neuropsychiatr Genet. 2011;156B(6):681-690.

57. Katzenberg D, Young T, Finn L, et al. A CLOCK polymorphism associated with human diurnal preference. Sleep. 1998;21(6):569-576.

58. Pedrazzoli M, Louzada FM, Pereira DS, et al. Clock polymorphisms and circadian rhythms phenotypes in a sample of the Brazilian population. Chronobiol Int. 2007;24:1-8.

59. Hu Y, Shmygelska A, Tran D, Eriksson N, Tung JY, Hinds DA. GWAS of 89,283 individuals identifies genetic variants associated with selfreporting of being a morning person. Nat Commun. 2016;7:10448.

60. Jones SE, Tyrrell J, Wood AR, et al. Genome-Wide Association Analyses in 128,266 individuals identifies new morningness and sleep duration loci. PLoS Genet. 2016;12(8):e1006125.

61. Broms U, Pitkäniemi J, Bäckmand H, et al. Long-term consistency of diurnal-type preferences among men. Chronobiol Int. 2014;31(2):182-188.

62. Chtourou H, Briki W, Hammouda O, Aloui A, Souissi N, Chaouachi A. The effect of the time-of-day of training during Ramadan on soccer players' chronotype and mood states. Sport Sci Health. 2014;10:143-147.

63. Czeisler CA, Kronauer RE, Allan JS, et al. Bright light induction of strong (type 0) resetting of the human circadian pacemaker. Science. 1989;244:1328-1333.

64. Wright KP Jr, McHill AW, Birks BR, Griffin BR, Rusterholz T, Chinoy ED. Entrainment of the human circadian clock to the natural light-dark cycle. Curr Biol. 2013;23:1554-1558.
ChronoPhysiology and Therapy

\section{Publish your work in this journal}

ChronoPhysiology and Therapy is an international, peer-reviewed open access journal focusing on research into the cyclic variations and rhythmicity in physiological processes in the body and the research and development and optimal timing of administration of therapeutic targets to achieve improved outcomes and quality of life for the patient. The

\section{Dovepress}

manuscript management system is completely online and includes a very quick and fair peer-review system. Visit http://www.dovepress.com/ testimonials.php to read real quotes from published authors. 